\title{
RETHINKING THE OPEN METHOD OF COORDINATION: MUTUAL LEARNING INITIATIVES SHAPING THE EUROPEAN RESEARCH ENTERPRISE
}

\author{
Merli Tamtik \\ University of Toronto
}

\begin{abstract}
Since 2000, the Open Method of Coordination (OMC) has become a policy approach increasingly used in the European policy making process. By focusing on research policy, this study examines the ways in which the OMC and the mutual learning initiatives have influenced the wider policy discourse in the European Union. The paper argues that it is important to think about the contributions of the OMC in research policy in more broad and fundamental ways. This theory-guided study takes an empirical approach to the OMC, providing significant evidence on mutual learning effects analyzed in terms of developing an authentic dialogue, shaping policy discourse, shaping policy networks and facilitating collaborative learning. The analysis reveals that the OMC changes the ways in which the representatives from the Member States and the European Commission contribute to research policy, leading to a promising foundation for further policy enhancement.
\end{abstract}




\section{Introduction}

The last couple of decades have witnessed an intense search for new public policy approaches that can effectively address complex social and economic problems (Nilsson et al. 2008). Governments are increasingly emphasizing the need for evidence-based policy as an essential path to informed policy decisions. Scholarly literature has focused on analyzing the importance of research evidence in decision making (Hammersley 2005; Bogenschneider and Corbett 2010), the significance of professional knowledge in policy-making (Nutley et al. 2007; Culyer and Lomas 2006), and the benefits of employing analytical assessment tools to prove effectiveness of policies (Radaelli 2004; Nilsson et al. 2008). While these outcome-oriented rational policy approaches are useful and anticipated, scholars note that policy change is usually a long term dynamic process that cannot be understood solely in linear terms (Kingdon 1984; Sabatier 1986). It is the individual ideas, concepts and policy beliefs that shape the policy outcome over extended periods of time (e.g. Sabatier 1986; Jacobs 2009). The pressure to produce and evaluate policy results has often left the process of policy conversation itself in the shade. To make better use of evidence and foresee potential policy outcomes, it is of crucial importance to understand the nuances of the agency of individuals in cooperation with others, and the dynamics of how policy ideas shape the course of a policy process.

Research policy in the European Union (EU) is a field where a variety of interests, ideas, and policy beliefs meet. In the drive for increased economic competitiveness, EU policy makers are aiming for a better coordinated and more integrated policy approach (Van Vught 2010). Member States, on the other hand, demonstrate considerable resistance towards EU level policy intrusion (Gornitzka 2007). In this diffuse policy environment, an array of policy instruments has been developed to deliver policy outcomes. In 2000, the European Union introduced a unique policy approach where policy makers and experts from the Member States and the European Commission (EC) get together, discuss policy ideas, and study from each other in a consciously constructed learning environment. This policy approach is called the Open Method of Coordination (OMC). This method is unique as it is a strategic attempt to bring together experts from diverse socio-economic and cultural environments (27 EU Member States and associated countries) to discuss specific policy areas, explore solutions, share country-specific examples, and at the end, design policy recommendations applicable for diverse national settings.

The OMC approach has triggered a significant amount of criticism from scholars who mainly point to the limited nature of any tangible policy change at the national or European level (e.g. Kaiser and Prange 2004; Szyszcak 2006; Kröger 2009a). This study proposes that the impact of the Open Method of Coordination should not be understood purely in instrumental terms but should also be analyzed in terms of broader conceptual shifts taking place over longer periods of time.

This study is guided by the following research question: How does the OMC mutual learning initiative contribute to and shape the European research policy? It analyzes initiatives of the OMC working groups where the focus is on the process of policy development rather than specific outcomes that have been translated into policy change. The author hypothesizes that the OMC mutual learning exercises impact the dynamics among actors, thus preparing grounds for collaboration and ultimately fostering new approaches to policy making. The author argues that the OMC changes the ways in which participants think about policy problems, which in turn lays 
a solid foundation for enhancing European research policy. The study takes a theory-guided empirical approach to the $\mathrm{OMC}$, providing significant empirical evidence to support the hypothesis.

\section{Open Method of Coordination in Research Policy: The Existing Argument}

The Open Method of Coordination is a policy making method of the European Union and its Member States characterized by voluntary policy coordination through mutual learning initiatives (Borrás and Radaelli 2010). The process is set up as a non-binding, bottom-up initiative where the decision making power lies in the hands of the Member States. The process is guided and facilitated by the European Commission, which analyzes the progress reports and disseminates recommendations for each of the Member States (Van Vught 2010). Ruiter (2010) lists four initiatives that form the infrastructure of the OMC: 1) guidelines or objectives, 2) indicators and benchmarks, 3) National Action Plans (NAPs) or National Reform Programmes (NRPs), and 4) peer-learning groups. These tools are set up for monitoring and evaluating the progress of policy coordination among the Member States with the aim of achieving greater economic development in the region. It has a cyclical nature (typically yearly, sometimes in three year cycles) where Member States report to the European Commission on its achievements and progress. The OMC is very closely linked to research and innovation policies. It was first introduced in 2000 and was seen as the main instrument to reach the ambitious goals of the Lisbon Strategy for economic competitiveness - to become "the most competitive and dynamic knowledge-based economy"(European Parliament, 2000). The diversity of the research systems across the EU Member States has been a significant challenge in delivering the goals of the Lisbon Strategy. As noted by Kaiser and Prange (2004), the variations in legislative and budgetary powers lead to different research and innovation policies; the range of institutions and national coordination mechanisms along with a remarkable diversification in research performance prevent achieving common European research policy. In addition, there is a considerable resistance among the Member States to allow European interference in national research policies (Gornitzka 2009). To ensure better integration of national research policies, the political leaders agreed to work towards creating the European Research Area (ERA), a concept to improve the effectiveness and efficiency of the fragmented European research landscape (Van Vught 2010). In research policy, the OMC was seen as an instrument for intergovernmental policy analysis and was expected to provide the formal setting for initiating policy debates among countries in areas of research and innovation. As a "soft" policy instrument, the method was designed to use peer pressure and "naming and shaming" as opposed to legal interference in order to create stronger member state involvement in the development of European research policy (Van Vught 2010).

One of the crucial dimensions in the dynamics of the OMC is policy learning, through a process of incorporating individual agency at the level of policy ideas and beliefs. Policy learning is understood as a process of updating one's beliefs or changing one's views about key components of policy through social interaction (Zito and Schout 2011; Radaelli 2009). Several authors have emphasized the importance of learning capacity, linking it to one potential mechanism for gradual policy change (Lundvall et al. 2002; Zito and Schout 2011; Radaelli 2009). Nilsson et al. (2008) state that everyday policy making is part of a long term process of learning and strategizing, in which common views and political coalitions are constantly formed and reconstituted over time. While analyzing policy making in the EU, Eising (2002), argues that 
as a result of policy learning and knowledge exchange, countries' basic policy preferences can change. Zahra and George (2002) note that the capacity to absorb information through learning allows organizations and institutions to better adapt to their changing environments and have an advantage over their competitors. Lundvall et al. (2002) argue that interactive policy learning can lead to innovation and increased economic performance. Some authors believe that policy change resulting from gradual knowledge accumulation through learning can have long lasting and more stable policy results (Lundvall et al. 2002). Therefore, policy learning is often seen as a tool for "a soft mode of governance" where change is triggered through voluntary mechanisms without legal interference (Borrás and Conzelmann 2007; Kröger 2009a; Van Vught 2010). Policy learning is used in the OMC as a way of motivating Member States to participate and engage actively in policy processes. Learning from each other and considering best practices of others is expected to enhance policy coordination through the OMC. The White Paper on European Governance articulates the aim of the OMC as follows:

The open method of co-ordination is used on a case by case basis. It is a way of encouraging co-operation, the exchange of best practice and agreeing on common targets and guidelines for Member States, sometimes backed up by national action plans as in the case of employment and social exclusion. It relies on regular monitoring of progress to meet those targets, allowing Member States to compare their efforts and learn from the experience of others. (European Commission 2001, 20)

According to this statement, the primary goal of the OMC is not only achieving a set of indicators determined by the National Action Plans, but mainly facilitating discussions and enhancing cooperation among the Member States, in a situation where knowledge exchange and policy learning are set in the centre stage. The OMC is regarded as a process, where information and communication are used to shape a shared understanding of common policies (Van Vught 2010).

The main debate in the scholarly community has tended to focus on issues of the effectiveness and measurable outcomes of the OMC. The outcomes of the OMC have been analyzed in terms of national policy performance and change, effects on EU-level policy paradigms, effects on the transformation in EU law, and effects on governance patterns (e.g. Borrás and Greve 2004; Kröger 2009a; Borrás and Radaellli 2010). There are both supporters and critics of the OMC approach. The supporters mostly argue on the basis of the increased democratic transparency in EU policy making and the impact OMC has had for increased Europeanization (Borrás and Conzelmann 2007; Radaelli 2008). Szyszcak (2006) states that the OMC has helped increase the competence of the European Union to regulate areas where the traditional Community legislative processes had been weak (e.g. environmental policy) or where new areas require coordination of Member State policy (e.g. sustainable development strategies). De Elera (2006) argues that the European Research Area, with the help of the OMC in research policy, could potentially foster a European identity through the creation of common values. However, so far economic considerations have prevailed and the possibilities of civil society providing inputs for this policy have not been fully used. Room (2005) points out that the OMC recognizes the role of a wide range of actors, not just national governments, thus helping to alleviate criticisms about the lack of transparency in the EU's policy making. 
The absence of tangible results at the level of national policies has triggered most of the criticism in this area. Kröger (2009b), analyzing the changes in social policy in France and Germany, could not detect any significant effects as a result of the OMC. The author notes that the actual changes in social policy in these countries were taking place before the introduction of National Action Plans. Morano-Foadi (2008), making reference to the Italian research policy, has illustrated how the lack of a powerful enforcement mechanism in relation to the transfer of best practices in Italy has served as a challenge in achieving policy change at the national level. McGuinness and O'Carroll (2010) see the potential impact of the OMC on national research systems in achieving convergence, but not necessarily of a quantitative kind.

Lacking in this debate is a consideration of less visible and measurable change, which is crucial in terms of longer term policy effects. There is a lack of analysis of the primary goal of the $\mathrm{OMC}$ - the contribution to the common policy understanding and facilitation of policy learning that in the long run provide a foundation for stable policy results. There is a significant literature about the OMC and its relation to mutual learning (Nedergaard 2007; Radaelli 2008; Hartlapp 2009), but again, it is often critical of attempts to measure learning in relation to the outcomes of policy change (e.g. Radaelli 2008). There are many scholars who admit that the specific outcomes of policy learning are difficult to identify and practically impossible to quantify (McGuiness and O'Carroll 2010; Zeitlin 2011). These authors point to methodological reasons. The challenge lies not only in managing the variety of government systems within the EU countries, but determining a causal relationship of policy learning based on collaboration between EU institutions and Member State governments without any legally binding sanctions (Borrás and Greve 2004; Gornitzka 2007). Kröger (2009a) concludes that the general challenges with the OMC include too much information and too many documents along with too little time for discussion, language barriers and an emphasis on governmental reports rather than strategic plans, a lack of political elites in the OMC processes, a lack of transfer of what was eventually learned into the ministerial hierarchy, and institutional differences between welfare systems.

Zeitlin's (2011) study represents an example of recognizing the broader impact of the OMC process. His empirical research into the areas of employment and social inclusion shows that the OMC has been successful in many ways. First, it has contributed to the change in focus at the national level by introducing new ideas and concepts to the national policy debates that originate from the EU's policy discussions (e.g. lifelong learning, social inclusion). Second, it has contributed to better horizontal coordination and cross-sectorial integration of interdependent policy areas at the national level and enhanced vertical coordination between levels of governance (EU and country level). Third, the impact of mutual learning has led to the identification of common challenges and promising policy approaches at the EU level including statistical harmonization and capacity building (at both EU and national levels); it has also induced Member States to rethink established policy approaches and practices.

In spite of its criticism, the OMC process has not stopped. The most promising indicator seems to be the fact that all of the involved actors want to continue with policy learning as they find it a useful, valuable, and flexible means to harness the benefits of cooperation among the Member States (Warleigh-Lack and Drachenberg 2011). The European Commission's (2009) assessment of the OMC's influence (impact) on research policy states the continuous need to focus in the future on facilitating learning and strategic policy coordination rather than only exchanging information. The need to continue with mutual learning exercises through policy monitoring and coordination is continuously expressed and emphasized in various new strategic policy documents (e.g. Europe 2020, Innovation Union Communication). 


\section{Theoretical Framework}

This study is informed by the theory of collaborative governance where policy making is facilitated through dialogue in a consensus-oriented decision making process (e.g. Connick and Innes 2001; Innes and Booher 2003; Ansell and Gash 2008). The theory is useful in taking an alternative approach to the value assessment of the OMC. It focuses primarily on the process and the specific conditions needed to secure collaborative policy making. The theory emphasizes the dynamics of cooperation and competition among participants leading to new innovative knowledge through learning practices. Connick and Innes $(2001,9)$ understand collaborative governance as a process that includes "representatives of all relevant interests" and "engages various participants as they learn and interact." Ansell and Gash $(2008,544)$ take a more policyoriented approach and define collaborative governance as an arrangement where "one or more public agencies directly engage [non-]state stakeholders in a collective decision-making process that is formal, consensus-oriented, and deliberative and that aims to make or implement public policy or manage public programs or assets." This definition is useful as it focuses on the process and allows room for looking not only at policy outcomes (implementation) but management of policy initiatives in a broader sense.

How does this theory help us in understanding how changes in policy process are occurring? The theory proposes diversity and interdependence as two crucial conditions in establishing an authentic dialogue among participants (see Figure 1). Diversity is linked to competition as the representation of diverse interests leads to competing policy agendas. Interdependence is linked to cooperation as the policy agenda cannot be taken forward without relying on each other's knowledge, financial resources, or access to information. In this study, diversity is secured by involvement of a variety of actors (e.g. European Commission representatives, Ministry officials from country governments and area experts), each representing varied interests (e.g. political, professional, and/or personal). Mutual interdependence is maintained by a shared realization that only working together and relying on each others' expertise results in effective learning (e.g. working together helps to take the development of European research policy forward). As different ideas get proposed, discussed, and challenged, a conclusion needs to emerge that would respond to the various interests of the stakeholders. It requires considerable creativity to find actions that would respond to this wide set of competing interests and lead to innovative policy approaches. Based on this perspective, I hypothesize that diversity and interdependence matter in creating an authentic dialogue in the OMC process. Diversity triggers interests, allows collecting information on critical variables, allows policy comparisons, and ultimately contributes to learning (Sabatier 1986; Kaiser and Prange 2004). Interdependence of each other's knowledge and resources helps to develop creativity in proposing policy recommendations or starting new collaborative projects (Innes and Booher 2003). 


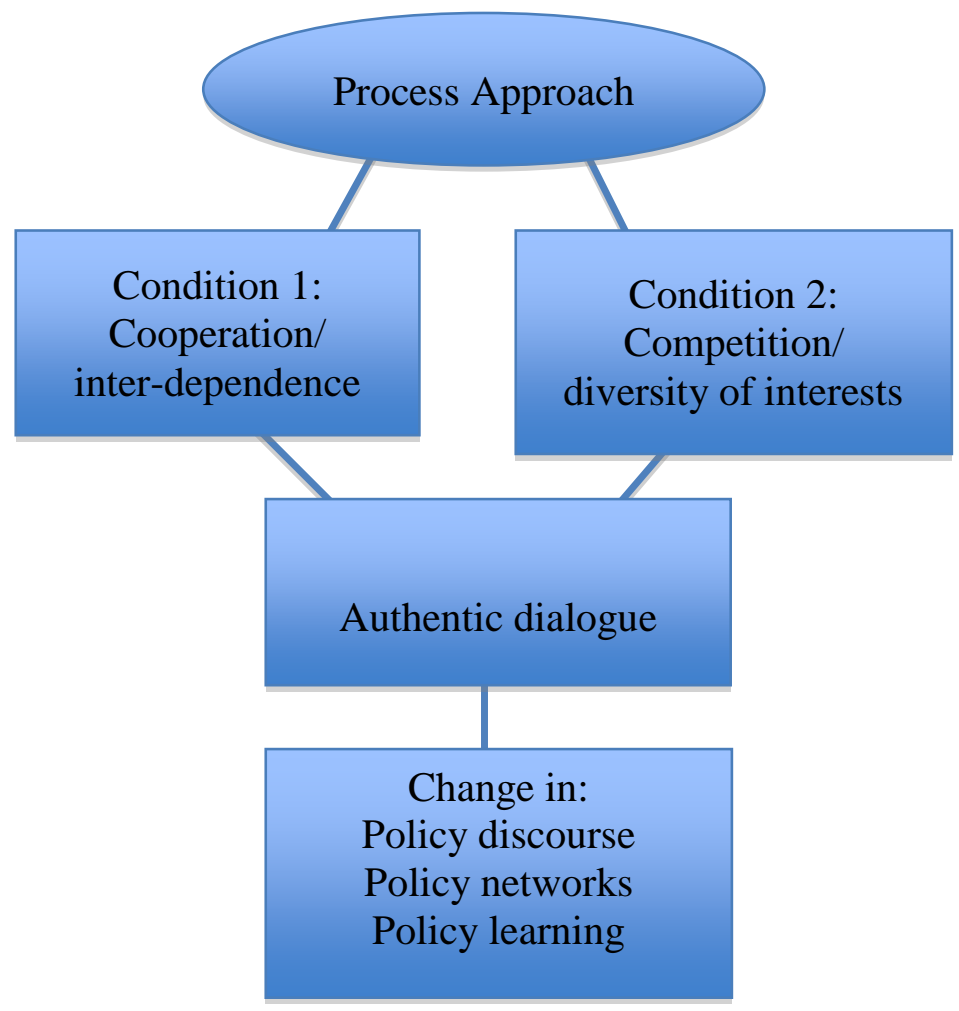

Figure 1. Authors' conceptualization based on the Theory of Collaborative Dialogue (Innes and Booher 2003).

This perspective suggests that changes resulting from the authentic dialogue are gradual and diffuse rather than instrumental and focused. Innes and Booher (2003) note that policy making in this framework should be analyzed not in terms of specific policy outcomes, but in terms of indicators relevant to the process itself such as the restructuring of policy networks and policy discourse, the emergence of social capital, empathetic relationships among participants, collective learning (what has been learnt), and increased capacity for innovation. As a result of collaboration among diverse groups of stakeholders (Member States, associated countries and the European Commission), it is the new combinations of policy groupings and emerging patterns of knowledge input that are important to assess, rather than specific policy changes, in order to understand significant nuances around the policy change process.

I will first analyze the potential change in policy discourse and hypothesize that the OMC influences policy discourse at multiple levels. At the European level, giving the full decision making power to the countries provides the Commission with the added incentive to move forward with developing European research policies, referring to the interests of and pressures from the Member States. At the national level, the involvement of high level government representatives in the European policy discussions makes possible a higher level of attention to the OMC process and its results nationally. In addition, experts involved in the process gain firsthand policy relevant information (best practices, strategic policy approaches) that might serve useful purposes and create increased competitive advantage to a country. Collected and disseminated knowledge (ideas and concepts) can enter policy debate gradually and have the potential to influence the policy debates when opportunity arises (Kingdon 1995). As the 
participation in the OMC process is voluntary, countries choose the topics in which to participate. It could be assumed that by making this choice to participate, there already is a potential opportunity for ideas to enter and shape the debate.

Then, I will examine the nature of policy networks. As noted by Ansell and Gash (2008), in collaborative governance new relationships are built among people who would ordinarily not talk to each other. The OMC process creates a situation where people from diverse contexts get engaged in a dialogue, developing trust, tolerance, and understanding among one other. I hypothesize that OMC discussions create new policy networks at multiple levels. I analyze how these networks among country experts and European Commission representatives are established and how these networks contribute to gradual change in policy making.

Finally, I seek to analyze if and how mutual learning happens. For learning to occur, participants need to be engaged in a task which they are capable of and in which they possess expertise (Ansell and Gash 2008). The specific institutional design (ground rules for collaboration) contributes to the process. As noted by Heritier (2002), usually groups that feel they have had a legitimate opportunity to participate are likely to develop a commitment to the process. The learning component is seen as an interaction where participants not only listen and ask questions of the experts, but also interact actively with one another around an issue. As a result of the collaborative policy dialogue, shared identities, meanings, new heuristics, and innovative policy solutions can emerge (Innes and Booher 2003). I hypothesize that learning occurs at the individual level through collaborative process when participants can explain their learning experience and describe specific examples on new knowledge gained.

Overall, the theory is useful in providing an alternative view on how to examine a policy initiative that is aimed at facilitating a dialogue and encouraging ownership of the policies among various stakeholders. As noted by Ansell and Gash (2008), policy makers might be more favourable to collaborative governance where they expect a difficult implementation process, as is potentially the case with the OMC in research policy. The categories stated above provide the analytical framework for examining the contributions of the OMC process in the development of the EU's research policy.

\section{Methodology}

This study employs a case study strategy to examine the contributions of the OMC to the overall dynamics of policy making in the field of research policy. In this field, the EU Competitiveness Council has appointed the ERAC (European Research Area Committee, formerly CREST) ${ }^{1}$ to oversee the implementation of the OMC. The ERAC is composed of the Member State representatives and the European Commission representatives that collaboratively make decisions on its activities. As one of its activities, the $\mathrm{OMC}$ in research policy has been implemented through a formation of theme-based expert groups. During yearly cycles, the Member States propose and the Commission endorses policy topics that would enhance mutual learning in various areas of research policy. Each Member State then nominates its area experts (typically mid-level policy makers within the relevant Ministries) to participate in the expert groups. The group has a significant freedom to operate. The group first has to select a Chair, then decide on its working methodology and agree on its expected outcomes. At the end of each cycle, working groups report back to ERAC, which draws conclusions and formulates policy recommendations. Typically, final policy recommendations are distributed among all Member

1. Comité de la recherche scientifique et technique, EU's Scientific and Technical Research Committee 
States (not only the participants of the group) in order to ensure a larger policy impact. Over the years, the topics for discussion have included public research spending, coordination of the Structural Funds and the Framework Program, internationalization of research and development $(\mathrm{R} \& \mathrm{D})$, effectiveness of fiscal measures stimulating $\mathrm{R} \& \mathrm{D}$, and intellectual property rights, among others. Selected OMC expert groups are set in the centre stage of the study, making possible an assessment of the broader effects of the OMC process, rather than simply assessing the guidelines, the level of indicators or the achievements of the National Action Plans (three other initiatives in the OMC process).

The "Structural Funds and the Framework Program" (Group 1) and "Internationalization of science and technology (S\&T)" (Group 2) of the OMC have been chosen as case studies for several reasons. First, both topics stimulated debates where complex and diverse national interests emerged, making the dynamics and power hierarchies among participating country experts especially apparent. The "Structural Funds and the Framework Program" expert group aimed for efficiency by encouraging the use of two European level financial instruments to support research initiatives. Newly joined EU Member States were eager to develop their infrastructure, especially in rural areas, and were not ready to integrate these two instruments, which they saw as representing opposite interests in regards to the older European Member States. The second group, working to develop EU strategy for international research collaboration, also had varied national interests represented in terms of potential research partners from third countries. Second, the time frame between the expert group meetings (Group 1 meetings were held in 2006, Group 2 meetings were held in 2006-07 and final policy recommendations provided in 2007 and 2009) make it possible to analyze the broader impact of those recommendations. Third, both groups were looking to influence policy making not only at the national level, but also at the European level, providing impetus for analyzing developments at both levels in regards to the contribution of the OMC.

This study has focused on collecting qualitative data on the OMC process. Such information is crucial in order to better understand and analyze the nuances in this policy approach. Two main methods and data sources have been employed. The first step involved content analysis of the OMC expert meeting reports and country-specific reports as examples of successful research cooperation initiatives. A content analysis has been carried out, identifying several themes concerning the nature, focus, and targets of these strategic documents (Weber 1996). Document analysis informed the basic understanding of the nuances in the OMC process (which countries/experts participated; the mandate of the working groups; the process and methodology used; the nature of the policy recommendations). Built upon the document analysis, the experts were identified and an interview protocol was designed.

The second step involved conducting semi-structured telephone interviews with country experts participating in the CREST OMC working groups. All participants with publicly available email addresses listed in the CREST final policy reports were invited to participate. That included experts from the 25 EU Member States and associated countries (N=42) and also representatives from the European Commission Directorate General (DG) Research and Innovation $(\mathrm{N}=8)$, involved in the groups as facilitators. A total of 19 country experts out of 15 Member States and associated countries were willing to participate in the study, and three European Commission facilitators were available. The telephone interviews were contacted in spring 2011 and spring 2012. The interviewees represented the following countries: Austria (1), Belgium (2), Czech Republic (1), Estonia (1), Germany (2), Greece (1), Hungary (1), Italy (1), Lithuania (1), Netherlands (2), Norway (1), Portugal (1), Romania (1), Spain (2) and Sweden (1). 
Among the country experts there were nine men and ten women, most of them working as government officials (typically in Ministries of Higher Education and Research). The interviews were used to clarify how the OMC process is viewed to be contributing to policy making and what factors were perceived to be shaping the process. As participation in the group was voluntary for the countries and policy recommendations had a non-binding nature, the threat that participating individuals would tend to overemphasize the importance of their participation, is minimal. Several informants were critical, referring to the lack of direct policy outcomes of their work.

In addition, in-person interviews with five European Commission policy makers (Head of Units (2) and mid-level administrators (3) from three Units: ERA Policy; Economic Analysis and Indicators; and Skills) within the DG Research and Innovation were conducted in Brussels during summer of 2012. These interviews with key informants were used to identify the broader policy developments over the past decade taking place in the European Commission DG Research and Innovation as a result of the OMC.

The interviews, ${ }^{2}$ on average of 50-minutes in length, were recorded and transcribed. Collected data was organized, coded, and analyzed following usual procedures (Miles and Huberman, 1994; Strauss 1987). Categorical themes were determined (open coding), establishing patterns of themes (axial coding, selective coding) and developing generalizations from the information provided through the interviews (Creswell 1998).

\section{Findings}

The empirical findings are analyzed first with respect to securing authentic dialogue-an environment necessary for the learning to happen. The presence of two important factorsdiversity and interdependence-will be explained to demonstrate the complexity of the policy setting. Then, the following three main categories, proposed by collaborative governance theory, will be analyzed: restructuring policy networks, restructuring policy discourse, and promoting collective learning. The intention is to explain how the OMC has contributed to and indeed changed European research policy.

\section{Creating an Authentic Dialogue}

The OMC can be characterized as a dynamic, diffuse and time consuming process, where the outcomes are extremely challenging to predict and influence. Policy making in the OMC mode is an environment where diversity and interdependence meet. The diversity that is represented in the process is threefold. First, the EC policy makers are trying to direct the process according to the EU's strategic directions. Second, there are country experts, sharing their professional field based expertise, on the one hand, while promoting their country's political views as national representatives, on the other hand. Third, as individuals, the experts bring to the process their own unique personal characteristics, which can also significantly shape the policy outcome. As one EC policy maker reflected:

It's difficult, very many different agendas get mixed up. Ultimately, it depends on people. Sometimes you can have a dominant personality playing a strong leading role

2. Please note that the author preserved the original language of interviewees, thus the quoted excerpts may include some minor grammatical errors. 
and you end up with a more successful process. Then you get some other group where there is a detractor, somebody who is pulling things back. So the success or failure is not dictated just by pure institutional arrangements that are put in place, but people, ultimately things get done by people.

Country experts noted the influence of political interests in the process:

I was representing [country] and of course also the national interests play an important role here. /.../ You need to avoid the fragmentation of national efforts. And our main interest was getting new ideas from other countries to help [country].

A different view from a country representative emphasized the contribution of a professional opinion that might have been different from the country's official standpoint:

I talked from my own professional experience. On my part, I was pretty high up in the hierarchy, so I could say what I thought was right, but I wouldn't bet on that my government would have the same opinion than I had.

Participating members were aware of their interdependence in taking the policy development forward. Experts in the OMC group saw a potential for enhancing policy coordination in Europe as a result of a mutual contribution based on shared values. Several participants were concerned about fragmentation of European level research policy. Most governments of the Member States are committed to create the European Research Area and enhance Europe as a region through research and innovation initiatives. The idea that European level policy coordination is important serves as one example of a shared policy belief among the country experts. The following comment is representative:

[W]e felt that it was time for a more systematic approach [at] the EU level to avoid the duplicity and segmentation. Because there were some activities at the Member States level and some things done by the European Commission, but nobody in fact knew what the other side was doing.

As stated above, most of the country experts involved in the OMC expert groups really were seeing the value of the OMC process helping to enhance the policy coordination. They actively contributed their knowledge and were concerned when the outcomes of their work were not clearly translated into visible policy change. However, not all participants were actively involved in the policy learning process as noted by several informants. According to several EC representatives, the resistance from some of the Member States towards contributing to the general vision for EU's research policy is still very much apparent. However, that did not come up when talking to participating country experts. The following quote is illustrative:

Then you also have different biases that different Member States bring to the table, you have some countries where all the officials maybe are instructed to take part in these types of processes but not necessarily contribute in a proactive manner but to use it more as basically intelligence collecting exercises. So they can then act in the "real" policy circles knowing what's going on, in order to minimize the EU's agenda. 
There are several important factors in creating an authentic dialogue based on diversity and interdependence. As noted by Innes and Booher (2003), stakeholders are often accustomed to concealing their interests and engaging in positional bargaining, rather than in honest discussion. It is important to create an open environment based on trust where diverse opinions are represented. The role of the group Chair is crucial in this process. The Chair must manage discussion so that participants feel comfortable and safe in saying what is on their minds even if they think others will not like it. According to the participant, that was mostly the case:

I think it was a very well-balanced group. Everything worked on equal principles. It was never a case that somebody wanted to talk but was not allowed. No, that wasn't the case at all.

The Chair of this group, [name], he is really a dynamic guy with lots of ideas and what was really important, he is working for an Executive Agency of the [country] government. So he knows all the concrete problems that you have in the field, also when it comes to more practical implementation of the policies. But he is a very dynamic person with lots of ideas, so I think that in the process he was a real driving factor in the whole group.

The fact that the dialogue evolved not only around best practices, but sometimes also around policy failures is another indication for an authentic dialogue. It was noted that the debate and the level of honesty in the group depended very much of the individual participants:

Certain people, they were very..., they talked about how things didn't work. That I liked. That was not of course country dependent, it depends on a people. (country expert)

As the recommendations were non-binding and participation voluntary, the participants could speak freely and in most cases represent their own professional knowledge. The following quotes illustrate the nature of the authentic dialogue:

I enjoyed the debates and arguments and the way reasoning was done. It was something very exciting.

It was rather smooth, the whole procedure of decision-making process in the group. We had not many differences and even if we had some differences, for example on the final report, and the wording, we were trying to find some solution on the wording by eliminating the most sharp differences, so we could live with the final outcome.

This complex policy environment, where diverse and sometimes conflicting interests meet, demonstrates why immediate policy results in European research policy have been slower and less visible than expected by some. The process, however, has had distinctive outcomes, characterized by change in policy discourse, rearrangement of policy networks and collective learning. These changes provide the prerequisites that enable broader shifts in policy making to take place. 


\section{Shaping Policy Discourse}

The start of the OMC process marks a significant change in the broader development of the EU's research and innovation policy. The OMC was introduced and applied to research policy three years after the adoption of the Lisbon Strategy, in 2003. As noted by Van Vught (2010) the OMC created an additional context for European policy making in the field of research. Up until 2003, the European research policy had a very limited scope and was mostly operating in the cycles of the Framework Programs (FPs), providing financial resources to the Member States based on their research proposals. The OMC process served as a trigger for the start of a gradual shift for the DG Research from operating as a funding agency towards becoming a policy developer and leader for shaping the European Research Area. An EC policy maker reported:

Research policy at the EU level was largely sort of monolithic affair. About every five years a new FP was adopted and the only policy discussion was what is the next set of thematic priorities going to be to fund research. So basically research policy at the EU level revolved around funding instruments and so the policy was no more than just a tactics or the strategy of the funding agency.

With the start of the OMC process, the Member States were provided with the formal and politically authorized setting to actively participate in the development of EU research policy. An opportunity to work via OMC created high expectations among the EC policy makers as well. It was seen as a process leading to results in areas where the Commission had no legal power for interfering. As in the field of research the power of the EC to shape national level policies was quite restricted and the hopes for the OMC to shape the policy developments in all of the areas were high. As an EC policy maker recalled: "basically the OMC when it was first applied to research was seen as THE way of doing policies beyond funding a research".

One of the first and significant policy discussions marking the change in policy discourse involved the issue of human capital-the researchers. Researchers' mobility was thoroughly discussed with the country representatives with respect to recruitment challenges, social security issues, visa problems, and training opportunities. This discussion produced several policy documents that were adopted by the Commission including the development and endorsement of "The European Charter for Researchers" and "The Code of Conduct for the Recruitment of Researchers" -two policy documents promulgated in 2005. ${ }^{3}$ This shift in policy discourse was regarded by the EC expert as follows:

You see, this was already something... that there was clearly a development of something a little bit more sophisticated than just a funding program.

In addition to developing several new policy documents that helped to guide and govern the implementation of European research policy, the early steps taken through the OMC process triggered noteworthy organizational changes at the EU level as well. One example of this is a setting up of a European level discussion forum aiming for developing large-scale research infrastructure projects - ESFRI (European Strategic Forum for Research Infrastructures). As noted in the comment below, the process did not involve representatives from every Member

3. For the Charter and Code of Conducts see http://ec.europa.eu/eracareers/pdf/am509774CEE_EN_E4.pdf 
State (probably due to a limited resource capabilities), nevertheless it was a step towards facilitating collaborative policy discussion that eventually led to over thirty different research partnerships with diverse pan-European interests represented.

They were putting in place a strategic forum called ESFRI - European Strategic Forum for Research Infrastructures. /.../ ESFRI and the whole process that has kicked off, has led to a gradual development in a project of a EU level that is really improving the efficiency and the effectiveness with which Member States set about developing a new scale of research infrastructures. (EC policy maker)

Some evidence on the shift in policy discourse at national level as a result of the OMC is also apparent. For example, a representative from Hungary described the lengthy process of getting people to think about possible collaborative synergies along the lines of research innovation when applying for infrastructure funding. This shift happened as a result of organizational change, where a specific administrative body was set up to coordinate the most efficient use of finances. One expert recalled:

I think it took about three or four years to have this coordination body set up. But finally it happened./.../ The aim was to coordinate and build synergies between the programs [Framework Program and the Structural Funds] and of course coordinate the funding./.../ It is really difficult, it was a totally different mindset to coordinate these effects because the purpose [of these programs] was totally different. After establishing this Coordination Body, the situation certainly improved. People began to think about the different sources of funding and the different purposes.

Another expert from Sweden recalled how the participation of the OMC expert group drew attention and raised the topic of research funding above the other discussion topics related to research. As a result of active participation in the OMC group, the variety of ways in which the funds could be used to better facilitate innovation became apparent and triggered intense policy discussions at the national level. The expert recalled:

The most important was that people started a long time discussion after many years when we discussed the next FP and the next SF. How could we do this better this time. I am not sure we have been successful but it is a little bit higher up in the agenda compared to the last time when we were working with the FP.

Several experts noted that participation in the OMC process helped partially strengthen or give an incentive for better focus of a policy discourse taken at the national level. For example, the expert from Germany noted that knowledge received from the OMC survey and subsequent discussions were applied to the further development of their national internationalization strategy in R\&D. The same was confirmed by the expert from Austria. A representative from Norway argued that in this work, they were expecting to strengthen the international cooperation dimension of their national policy directions: 
There was an expectation and potential for [country] to move from the more sort of initial ways of making international cooperation to a more deep and a more long term cooperation with larger commitments.

These examples illustrate the contributions OMC has made towards initiating policy discourse or strengthening an existing policy conversation both at the European and national level. Organizational change, inserting and maintaining focused policy discussions, initiating collaboration among diverse stakeholders, and taking the leading role in enhancing the European research policy are just some signals of the impact the process has had. Clearly, the OMC has not been the sole mechanism for enhancing research policy in Europe, but it has definitely triggered several significant developments that cannot be ignored.

\section{Shaping Policy Networks}

The findings show that the OMC process marks a novel way of establishing networks of experts and policy makers that did not exist before. These networks serve as additional channels for distributing information horizontally (among the area experts but also among the policy departments within the Commission) and vertically (between the EC and national Ministries). This information includes knowledge of each other's needs and capabilities, as well as discovering ways for further collaboration. As noted by Gornitzka (2010), interaction between sectors that are built on different principles is a fundamental dynamic of change. Eventually it can result in radical change if goals, interests, understandings, and actors from one sphere occupy another.

The intent to develop research policy that would be responsive to a wide array of policy issues and is based on increased cooperation, could be regarded as an operation on different principles. The start of the OMC process created a situation where the Commission had to provide leadership for initiating broader policy discussions, a role that DG Research had not fulfilled before. This created a situation where cooperation and additional knowledge from other units and departments in the Commission was needed. As an informant recalled:

You suddenly had an array of policy issues where DG Research, in order to try to move ahead with EU research policies, found itself now in building up linkages and dialogues with a lot of the other policy departments in the Commission. Something that it didn't have up until that point. There was no real sort of discourse with the other because DG Research has and still is considered to be a baby, an infant, something that is only beginning to grow, in terms of policy.

On one hand the DG Research experts had to start building linkages among the relevant policy units, but on the other hand it began to facilitate processes where Member States representatives could get together for knowledge-sharing purposes. One of the first settings that were created for that purpose was the ERA-NET scheme- a virtual network of national research councils, working voluntarily to enhance cooperation in areas of research and innovation. An EC expert who was involved in setting up this process emphasized the value of such an initiative:

We established ERA-NETs as a way to help public authorities to discuss among themselves, not at the level of diplomats, but at the level of the program managers in 
the Member States. They actually never met before, these guys! The ERA-nets were quite successful because they allowed people to share practices, how do you design, how do you implement, how do you evaluate program, how do you launch a proposal, what criteria do you use? And this whole thing at a very working level broke ice and allowed convergence of practices.

Another example of strengthening policy collaboration between the Member States and the EU is the establishment of the Strategic Forum for International Collaboration (SFIC) Advisory Body an instrumental outcome of the policy recommendations made by the OMC expert group in "Internationalization of R\&D with Third Countries." The Forum is currently composed of highlevel political representatives of the Member States and the European Commission. It aims at facilitating further development, implementation, and monitoring of the international dimension of European Research Area for joint research initiatives with partners outside Europe.

The country experts' view on the OMC initiatives where opportunities were provided for creating a space for policy discussions and learning has been seen as most positive. Several experts emphasized the benefit of meeting each other through the working group:

One of the good things about this group was that we met. We had this opportunity to meet each other and to discuss common problems, which we had and decide how to go together or how to plan cooperation.

The most important thing is that the networking not only between the Member States but also with the Commission officials, so you have that knowledge how expertise is shared and this is the most important thing in this exercise.

The discussions provided them with a chance to share their experiences, get to know each other, and openly discuss relevant issues. Many of these discussions apparently resulted in further strategic collaborations. Interdependence from each other's resources and knowledge helped to pave way to productive joint initiatives:

With the Germans and the Dutch we developed very strong ties. We even used one of their programs, so we had a lot of talk on how it worked and what were the conditions and how it was different in [country] and what we could do about it. (country expert)

There is an example among Romanian-German cooperation in India. Some part of this shared contract will be done in Romania and some in Germany. You don't have to double the effort to gain something. (country expert)

Clearly, the OMC has served as a start for further horizontal collaborations. If the need arises, area experts know who to contact, where to search for additional information or expertise, and how to act collaboratively. Experts have created a powerful network that is held together by shared knowledge and contacts created through the OMC. Collaborative policy making has become the principal policy making model in research policy. The creation and maintenance of a professional network provides a framework for an expert to be involved in the epistemic community that helps building legitimacy to influence and shape policy discourse (Haas 1992). 
The initiative taken by the DG Research for broader cooperation has lead to a situation where other units have begun to notice the developments taking place in research policy. The broader EU level policy discussions gradually began to include research and innovation initiatives among their strategic goals to fulfill the general vision for the region. In the Europe 2020 strategic policy document, research and innovation is included as one of the flagship areas for securing economic growth. This goal could be fulfilled through vertical collaboration, where individual experts play an important role in disseminating knowledge and gradually shaping mutual understanding for further steps needing to be taken for policy enhancement.

\section{Collective Learning}

In a collaborative dialogue, stakeholders and the views they represent can learn about one another's interests and problems, and they can change the way they view their own interests (Connick and Innes 2001). Hartlapp (2009) notes that OMC instruments provide distinctive contributions to learning, differentiating among 1) learning from one's experience, 2) learning from the experience of others, and 3) learning with others in a problem-solving setting. The findings indicate that policy learning in OMC working groups takes place in all of these categories.

Learning involved not only hearing what others were doing, but also becoming more knowledgeable of one's country's policy approach in comparative perspective. Evidence from learning from one's own experience was mentioned in regards to the groundwork that needed to be done when preparing for the meetings. The expert discussions involved a significant amount of preparation (collecting and synthesizing data, preparing presentations, and providing data and feedback based on their country-specific knowledge). These preparations provided a means to understand one's own situation better and then compare it with others. As was noted by one informant, this process involved engaging with the task and then "learning by doing" occurred:

We made presentations of national policies and national instruments, and initiatives in the research cooperation area, and that formed the basis for a discussion on similarities and differences regarding the approach to internationalization of research. /.../ I think it was very useful to benchmark of what we are doing in [country].

We provided information on what we do in [country], how we do it and why we do it. We presented the whole policy framework that provides direction to our efforts in the internationalization of research, we also presented some experiences in certain areas./.../It was a very useful experience.

Learning from the experiences of others was stated as a crucial motivating factor in participation at the working group. The experts gained knowledge in terms of learning about the policy ideas of others, processes that might have led to a policy result and the specific programs that others have successfully introduced. The following quote sums up the various learning expectations that came together:

There was an interest to learn how do they apply international collaboration, international programs for instance. What are the objectives behind the instruments, the tools to implement international cooperation. 
The informants provided several concrete examples of the ideas that in their opinion were useful to take on board. The cases, for example, included new ideas on how to enhance research cooperation in future:

We took ideas on board for example from France, Switzerland and UK. There were ideas in particular on science diplomacy, which influenced our thinking.

We took some ideas on board that we experienced from other countries, how they organize it. Especially with science councilors, we didn't have or we only had one science councilor, I think, we put more emphasis on having science councilors in other countries as well.

Learning about the processes involved several examples of know-how on how best to set up new programs or how to conduct productive lobbying in the EU circles to get a policy idea through:

In the case of the OMC group on fiscal measures where there was a very fruitful exchange, really detailed information on how fiscal incentives measures were set up in the different Member States. (EC policy maker)

In the expert group I learned, for example, how to promote our research capacities in the best way in Brussels because it is no use to promote just your own capacity, but you must join forces with the others, the other countries, so now we work usually together. (country expert)

There were a few examples of program learning where, during meetings, the expert was convinced that research cooperation with a particular country was important and needed to be enhanced. Based on the experiences of other Member States, where a specific cooperation was regarded as beneficial, the idea of initiating a new partnership was expressed "India should be one of the target countries for us, it was one of the target countries of this working group of internationalization."

The OMC primarily operates based on learning from the experience of Member States using best practices and benchmarking. However, a few references were made regarding learning not only from the best practices, but from the policy failures as well. Hearing about the failures was something not often discussed in the group. Understanding the factors and mechanisms why a policy approach did not succeed, was regarded as crucial for learning experiences. As a country representative reflected:

I was particularly very happy when somebody told about their failures. They talked about how things didn't work and why they didn't work. /.../ Because sometimes you can learn more from the failures then from the successes, what didn't work.

Collaborative learning experiences were apparent not only among the country experts; the participants of the Commission also found the experience equally enriching. Their learning included testing out policy ideas and being knowledgeable about the specific situations in the Member States in order to make suggestions and further policy recommendations. As the 
capacity to collect current information in a rapidly changing environment is essential, first-hand contacts with member state representatives provide valuable means for doing that. Several comments by the Commission representatives made this point:

For a Commission it was also an informal forum, a kind of test its own ideas in front of Member States in an informal way, especially as I said as we were preparing commissions communication. So we tested some ideas with the Member States.

Anything that has been generated in the OMC is de facto relevant to EU policy. We have to know our Member States, we have to know the policies and so on.

Learning with others is regarded in terms of created mutual understanding among participants, developing reciprocity, and collaborative relationships. The importance of mutual learning was expressed in terms of creating ownership of the policy ideas and recommendations. Several informants noted the value of creating shared standpoints:

It is important [to facilitate learning]. What we need to do is... we need to get ownership of the agenda into the hands of the people of the Member States, that's what ultimately going to make things happen at the local and regional level. And if you don't have that ownership, you can forget it.

People share the agenda, they own the thing, and then there is a collective willingness and understanding about what it is that needs to be done.

Overall, the findings point to the collective acceptance and ownership of policy ideas. Therefore, the improved capacity for innovation should be regarded in terms of pooling knowledge, gaining the ownership of policy recommendations, and a better understanding of the diversity of views, all necessary requirements for taking the development of the EU's research policy forward. That can happen only in mutual collaboration and contribution by the Member States.

\section{Conclusion and Discussion}

This paper focuses on analyzing the contributions of the OMC expert groups to the EU's research policy through mutual learning activities. The main critique of the OMC has been that due to its "soft-law," voluntary and non-binding character, it does not affect the Member States' polices and policy making. As there are no significant sanctions involved, other than peer pressure and naming and shaming, the Member States' governments are not committed to follow the policy recommendations. The argument often made is that there have been no concrete indications of change in national policies. Nevertheless, Member States and the European Commission representatives have expressed an interest to continue with policy learning, as they find it a useful and flexible means to harness the benefits of cooperation (Warleigh-Lack and Drachenberg 2011).

This paper argues that the impact of the OMC process should be understood in terms of less visible and broader changes in the dynamics of policy making. The paper examines changes in terms of restructuring policy discourse, restructuring policy networks and promoting 
collaborative learning. At the beginning of this paper, a tentative hypothesis was presented suggesting that diversity and interdependence enhance an authentic dialogue. The findings indicate that the diversity and interdependence found in the policy environment are significant conditions for policy learning and policy change to happen. The variety of opinions and experiences made the process enjoyable as the experts engage in the debate and a process of learning. The fact that experts discussed not only best practices, but also policy failures indicates that the trust was built among the participants. Another factor indicating the presence of an authentic dialogue is the fact that everybody had an equal opportunity to speak and was listened is. Clearly, the role of the Chair in handling the process is very important. As the group needed to come up with the final policy solutions, interdependence is present when aiming for a solution. This outcome correlates with Gornitzka's (2010) suggestion that differences in stakeholders' views, interests and goals serve as a fundamental driver for policy change.

The second hypothesis suggested that the OMC process influences policy discourse at multiple levels. The findings reveal that there has occurred a change in policy discourse both at the European level and at the national level. The most visible change resulting from the OMC expert group discussions was apparent in a shift towards initiating broader policy discussions at the Commission. The input received through the OMC discussions from the Member States served as a trigger in becoming more than just a funding agency, but providing strategic policy directions for taking the EU level research policy forward. In the national dialogue there were also perceptions indicating heightened attention towards the topics discussed in the OMC working groups as well as strengthening policy discourse that had been recently taken by governments. These developments indicate how ideas distributed through OMC policy conversations have the power of fostering policy ideas further. The question remains how the balance of policy interest is maintained so that the view of every participant is equally respected and represented.

The third hypothesis that proposed formation of new policy networks through the OMC process got confirmed. The OMC expert groups serve as one of the mechanisms for establishing unique policy channels for distributing policy relevant information. Area experts and policy administrators in the field of research policy did not have the opportunity to meet each other and discuss practices before. These contacts seemed to continue in several cases after the group work had officially ended. These OMC expert groups have allowed information to flow horizontally between governments of the Member States, between area experts and the Commission policy makers from different units. They have also enhanced vertical information flow between the Commission and the Member States. Experts as professionals participate in the process to build up professional knowledge, which allows them to increase their authority locally. For the EC representatives, the involvement of diverse stakeholders helps to project the idea of inclusiveness and transparency in decision making.

Research and innovation policies have been sensitive discussion topics among the EU Member States for decades. Scientific cooperation has been traditionally viewed as enhancing the competitiveness of the nation states where Member States are not eager to hand decision making capacity over to the European Union (Gornitzka 2009). The fourth hypothesis stated the presence of learning through the OMC. Through collaborative learning practices, Member States have expressed openness to share ideas and talk about challenges through their participation in the OMC initiatives, an activity that was absent before. Evidence was presented in terms of learning about policy ideas, programs and processes that have contributed towards policies at national level. Overall, the most important contribution of the OMC expert groups is that it 
provides a formal setting where diverse interests can be presented, discussed and learned from. In this process of collaboration, the participants build trust, become aware of the various arguments and gradually build common understanding, necessary for taking a policy dialogue forward. As noted by Innes and Booher (2003) the processes of collaborative dialogue helps to create a more adaptive and intelligent policy system in general. To conclude, the OMC might not have created visible immediate shifts in terms of policy change, but it has definitely built a strong foundation for policy transformations in the future.

\section{ACKNOWLEDGEMENTS}

The author would like to thank Professor Hubner, Professor Sá, Professor Hayhoe, and one anonymous reviewer for their most valuable comments and feedback that helped improve this paper. In addition, the author is truly grateful for the country experts and the EC representatives' willingness to share knowledge and expertise on the OMC process.

\section{REFERENCES}

Ansell, Chris, and Alison Gash. 2008. "Collaborative Governance in Theory and Practice". Journal of Public Administration Research and Theory 18: 543-71.

Bogenschneider, Karen, and Thomas J. Corbett. 2010. "Evidence-based Policy Making: Insights from Policy-Minded Researchers and Research-Minded Policy Makers”. New York: Routledge.

, Susana, and Thomas Conzelmann. 2007. "Democracy, Legitimacy and Soft Modes of Governance in the EU: The Empirical Turn." Journal of European Integration 29 (5): 53148.

Borrás, Susana, and Bent Greve. 2004. “Concluding Remarks: New Method or Just Cheap Talk?"Journal of European Public Policy 11 (2): 329-36.

, Susana, and Claudio Radaelli. 2010. "Recalibrating the Open Method of Coordination: Towards Diverse and More Effective Usages". Swedish Institute of European Policy Studies 7: $1-100$.

Connick, Sarah, and Judith Innes, J. 2001. "Outcomes of Collaborative Water Policy Making: Applying Complexity Thinking to Evaluation.” Journal of Environmental Planning \& Management 46 (2): 177-98.

Creswell, John W. 1998. Qualitative Inquiry and Research Design. Choosing Among Five Traditions. Thousand Oaks, CA: Sage Publications.

Culyer, Tony, and Jonathan Lomas. 2006. "Deliberative Processes and Evidence-Informed Decision Making in Healthcare: How Do They Work and How Might We Know?" Evidence \& Policy 2: 357-71.

De Elera, Álvaro. 2006. “The European Research Area: On the Way towards a European Scientific Community?” European Law Journal 12 (5): 559-74.

Eising, Rainer. 2002. "Policy Learning in Embedded Negotiations: Explaining EU Electricity Liberalization.” International Organization 56 (1): 85-120. 
European Commission. 2001. European Governance. A White Paper. http://ec.europa.eu/governance/white_paper/index_en.htm.

- 2009. The Open Method of Coordination in Research Policy: Assessment and Recommendations. www.era.gv.at/attach/omc_coordination_2009.pdf

European Parliament. 2000. Lisbon European Council Presidency Conclusions. http://www.europarl.europa.eu/summits/lis1_en.htm.

Gornitzka, Åse. 2007. "The Lisbon Process: A Supranational Policy Perspective. Institutionalizing the Open Method of Coordination." In University Dynamics and European Integration, edited by Peter Maassen and Johan P. Olsen, 155-78. Dordrecht: Springer Publishers.

- 2009. "Research Policy and the European Union-Multi-layered Policy Change?" In The Research Mission of the University. Policy Reforms and Institutional Response, edited by P. Clancy and D. Dill, 53-75. Rotterdam: Sense Publishers.

- 2010. "Bologna in Context: A Horizontal Perspective on the Dynamics of Governance Sites for a Europe of Knowledge.” European Journal of Education, 45 (4): 535-48.

Haas, Peter M. 1992. "Introduction: Epistemic Communities and International Policy Coordination.” International Organization 46: 1-36.

Hammersley, Martyn. 2005. "Is the Evidence-Based Practice Movement Doing More Good Than Harm? Reflections on Iain Chalmers' Case for Research-Based Policy Making and Practice." Evidence \& Policy 1 (1): 85-100.

Hartlapp, Miriam. 2009. "Learning about Policy Learning. Reflections on the European Employment Strategy." European Integration Online Papers-Eiop 13.

Heritier, Adrienne. 2002. "New Modes of Governance in Europe: Policy-Making without Legislating?" Social Science Research Network. http://papers.ssrn.com/sol3/papers.cfm?abstract_id=299431 .

Innes, Judith E., and David E. Booher. 2003. "Collaborative Policymaking: Governance through Dialogue." In Deliberative Policy Analysis: Understanding Governance in the Network Society, edited by Maarten A. Hajer and Hendrik Wagenaar, 33-59. Edinburgh: Cambridge University Press.

Jacobs, Alan. 2009. "How Do Ideas Matter? Mental Models and Attention in German Pension Politics.” Comparative Political Studies 42 (2): 252-79.

Kaiser, Robert, and Heiko Prange. 2004. "Managing Diversity in a System of Multi-Level Governance: The Open Method of Co-ordination in Innovation Policy". Journal of European Public Policy 11 (2): 249-66.

Kingdon, John. 1984. Agendas, Alternatives, and Public Policies. New York, NY: Harper Collins.

Kröger, Sandra. 2009a. "The Open Method of Coordination: Underconceptualisation, Overdetermination, De-politicisation and Beyond". In What We Have Learnt: Advances, Pitfalls and Remaining Questions in OMC Research, European Integration Online Papers (EIoP), Special Issue 1 (13), Art. 5, edited by Sandra Kröger. http://eiop.or.at/eiop/texte/2009005a.htm.

- 2009b. "The Effectiveness of Soft Governance in the Field of European Anti-poverty Policy: Operationalization and Empirical Evidence." Journal of Comparative Policy Analysis: Research and Practice 11 (2): 197-211.

Lundvall, Bengt-Ake, Bjorn Johnson, Espen S. Andersen, and Bent Dalum. 2002. "National Systems of Production, Innovation and Competence Building." Research Policy 31: 213-31. 
McGuinness, Nina, and Connor O’Carroll. 2010. “Benchmarking Europe's Lab Benches: How Successful has the OMC been in Research Policy?" Journal of Common Market Studies 48 (2): 293-318.

Miles, Matthew B., and Michael A. Huberman. 1994. Qualitative Data Analysis: An Expanded Sourcebook. Thousand Oaks, CA: Sage Publications.

Morano-Foadi, Sonia. 2008. "The Missing Piece of the Lisbon Jigsaw: Is the Open Method of Coordination Effective in Relation to the European Research Area?" European Law Journal 14 (5): 635-654.

Nedergaard, Peter. 2007. "Maximizing Policy Learning in International Committees: An Analysis of the European Open Method of Cooperation (OMC) Committees." Scandinavian Political Studies 30: 521-546.

Nilsson, Måns, Andrew Jordan, John Turnpenny, Julia Hertin, Bjorn Nykvist, and Duncan Russel. 2008. "The Use and Non-Use of Policy Appraisal Tools in Public Policy Making: An Analysis of Three European Countries and the European Union". Policy Sciences 41: 335-55.

Nutley, Sandra, Isabel Walter, and Huw T.O. Davies. 2007. Using Evidence: How Research Can Inform Public Services. Bristol, UK: The Policy Press.

Radaelli, Claudio. 2004. "The Diffusion of Regulatory Impact Analysis-Best Practice or Lesson-Drawing?” European Journal of Political Research 43: 723-47.

- 2008. "Europeanization, Policy Learning, and New Modes of Governance". Journal of Comparative Policy Analysis 10 (3): 239-54.

—. 2009. "Measuring Policy Learning: Regulatory Impact Assessment in Europe." Journal of European Public Policy 16 (8): 1145-64.

Room, Graham. 2005. "Policy Benchmarking in the European Union: Indicators and Ambiguities." Policy Studies 26 (2): 117-32.

Ruiter, Rik. 2010. "Variations on a Theme. Governing the Knowledge-Based Society in the EU through Methods of Open Coordination in Education and R\&D." European Integration 32 (2): 157-173.

Sabatier, Paul A. 1986. "Top-down and Bottom-up Approaches to Implementation Research: A Critical Analysis and Suggested Synthesis.” Journal of Public Policy 6: 21-48.

Schneider, Mark, John Scholz, Mark Lubell, Denisa Mindruta, and Matthew Edwardsen. 2003. "Building Consensual Institutions: Networks and the National Estuary Program." American Journal of Political Science 47: 143-58.

Susskind, Lawrence, and Jeffrey Cruikshank. 1987. Breaking the Impasse: Consensual Approaches to Resolving Public Disputes. New York: Basic Books.

Strauss, Anselm L. 1987. Qualitative Analysis for Social Scientists. Cambridge, UK: Cambridge University Press.

Szyszczak, Erika. 2006. "Experimental Governance: The Open Method of Coordination." European Law Journal 12 (4): 486-502.

Tett, Lyn, Jim Crowther, and Paul O'Hara. 2003. "Collaborative Partnerships in Community Education." Journal of Education Policy 18: 37-51.

Van Vught, Frans A. 2010. "The European Union." In National Innovation and the Academic Research Enterprise, edited by D. Dill and F. van Vught, 148-207. Baltimore: John Hopkins University Press.

Warleigh-Lack, Alex, and Ralf Drachenberg. 2011. "Spillover in a Soft Policy Era? Evidence from the Open Method of Co-ordination in Education and Training." Journal of European Public Policy 18 (7): 999-1015. 
Warner, Jeroen F. 2006. "More Sustainable Participation? Multi-Stakeholder Platforms for Integrated Catchment Management". Water Resources Development 22 (1): 15-35.

Weber, Robert P. 1996. Basic Content Analysis (6th edition). Newbury Park, CA: Sage Publications.

Zahra, Shaker A., and Gerard George. 2002. "Absorptive Capacity: A Review, Reconceptualization, and Extension”. Academy of Management Review 27 (2): 185-203.

Zeitlin, Jonathan. 2011. "Towards a Stronger OMC in a More Social Europe 2020: A New Governance Architecture for EU Policy Coordination." In Europe 2020: Towards a More Social EU? edited by E. M. and D. Natali, with Rudi Van Dam, 253-73. Brussels: P.I.E.

Zito, Anthony R., and Adriaan. Schout. 2011. "Learning Theory Reconsidered: EU Integration Theories and Learning”. Journal of European Public Policy 16 (8): 1103-23. 
Correct citation: Tamtik, Merli. 2012. "Rethinking the Open Method of Coordination: Mutual Learning Initiatives Shaping the European Research Enterprise." Review of European and Russian Affairs 7 (2): 1-24.

Published by the Centre for European Studies at Carleton University, Ottawa, Canada. Available online at: www.carleton.ca/rera/

RERA is an electronic academic peer-reviewed journal that publishes graduate, post-graduate, and young scholarly works. Topics relate to the European Union, its Member States, the former Soviet Union, and Central and Eastern Europe. The journal is a joint project supported by the Canada-Europe Transatlantic Dialogue - a cross-Canada research network supported by the Social Sciences and Humanities Research Council of Canada (SSHRC) - along with the Institute of European, Russian and Eurasian Studies (Carleton University) and its associated research unit, the Centre for European Studies.

RERA aims to provide an accessible forum for research, to promote high standards of research and scholarship, and to foster communication among young scholars.

\section{Contact:}

Carleton University

The Centre for European Studies

1103 Dunton Tower

1125 Colonel By Drive

Ottawa, ON

K1S 5B6

Canada

Tel: +01 613 520-2600 ext. 1179; E-mail: rera-journal@ carleton.ca

\section{Creative Commons License}

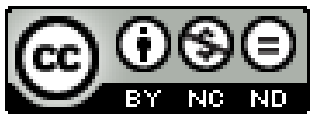

http://creativecommons.org/licenses/by-nc-nd/3.0/

This Working Paper is licensed under a Creative Commons Attribution-Non-CommercialNo Derivs 3.0 Unported License (CC BY-NC-ND 3.0).

Articles appearing in this publication may be freely quoted and reproduced provided the source is acknowledged. No use of this publication may be made for resale or other commercial purposes.

ISSN: $1718-4835$

(C) 2012 The Author(s) 